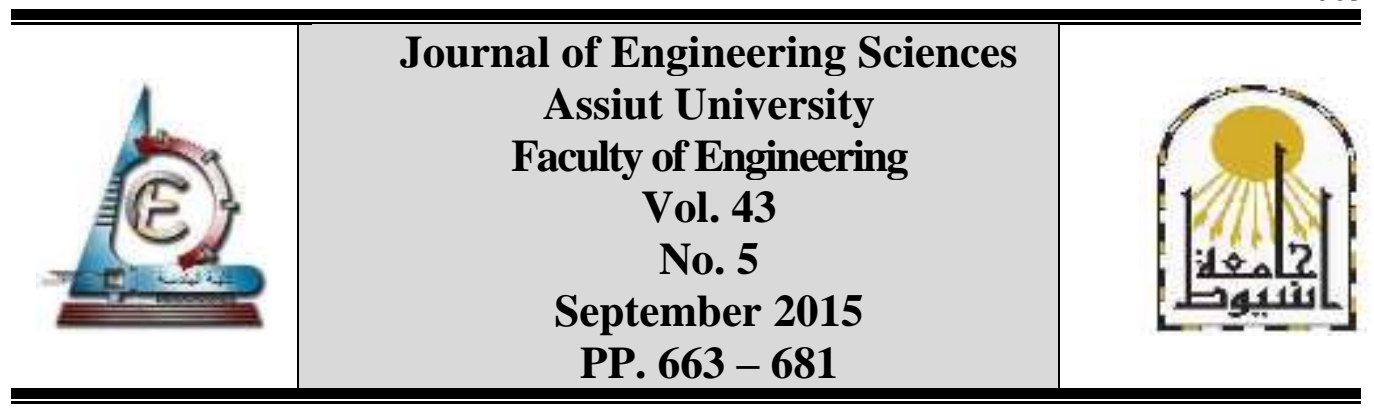

\title{
IMPROVING THE MECHANICAL AND DURABILITY PROPERTIES OF CEMENT MORTAR BY NANO TITANIUM
}

\author{
Mohamed S. Khalafalla ${ }^{*, 1}$, Osama A. Hodhod ${ }^{2}$, Ihab A. Adam ${ }^{3}$ \\ ${ }^{1,3}$ Construction Research Institute, NWRC \\ ${ }^{2}$ Faculty of Engineering, Cairo University
}

(Received 12 August 2015; Accepted 12 September 2015)

\begin{abstract}
Cement Mortar is the primary component of cementitious composites. Therefore, it has almost importance for concrete structures. Cement mortar rendering is usually used as a protective layer for most structural elements. The properties of cement mortar incorporating nano titanium were experimentally studied. Nano titanium is a very fine material, which plays a vital role in filling the pores between crystals. This property can lead to better mechanical and physical properties of cement mortar. The experimental results show that compressive and flexural strength gain of cement mortar improves until the added nano titanium reaches $1 \%$ of cement weight by $27 \%$ and 6 $\%$ respectively. Furthermore, porosity of cement mortar incorporating $1 \%$ nano titanium climbs to improvement level of $30 \%$ over plain samples. In addition, the results show an increase in the specimen's density by $5 \%$, over control samples.
\end{abstract}

Keywords: Mortar; Nanotechnology; $\mathrm{Nano}_{-} \mathrm{TiO}_{2}$; Compressive strength; Flexure strength; Microstructure; Durability, Porosity, ITZ.

\section{Introduction}

Recent researches conclude that the structural elements and phenomena that occurs at the micro and nano scales are main factors enhancing the overall behaviour of concrete materials. So, the researchers aim to modify the molecular structure of concrete by nanotechnology which leads to enhancing bulk properties of materials such as mechanical properties (compression, flexure, splitting etc.), and physical properties (volume stability, durability, and sustainability of concrete etc.). This revolutionary effect accompanying nanotechnology allows cost-effective designs, and enhances concrete performance, which can lead to unprecedented uses of concrete materials. Knowledge at the nano scale of the structure and characteristics of materials (known as nano characterization) will support the development of new applications and new products to enhance the properties of construction and rehabilitation materials. Calcium-silicate-hydrate $(\mathrm{C}-\mathrm{S}-\mathrm{H})$ gel is

\footnotetext{
* Corresponding author.

Email address: mhamedsmr@gmail.com
} 
responsible for the physical and mechanical properties of cement-based materials, including creep, shrinkage, permeability, porosity and elasticity [1].

\section{Definitions}

To understand the enhancement mechanism of cement mortar, the following definitions should be clarified.

Nano scale [2]: Anything from one hundred or more down to a few nanometres, or $10^{-9} \mathrm{~m}$

Nanomaterials [2]: A particle with at least one dimension less than $100 \mathrm{~nm}$.

Durability: Ability to resist weathering action, chemical attack, abrasion, or any process of deterioration

\section{Review}

Nazari et. al. [3] studied flexural, indirect tensile strength and setting time of concrete by partial replacement of cement with nano titanium (NT). NT with average diameter of $15 \mathrm{~nm}$ was utilized with different contents by weight, they concluded that the more content of NT the more flexural strength capacity. On the other hand, the use of NT up to $2.0 \%$ produced concrete with improved splitting tensile strength. However, the ultimate compressive strength of concrete was achieved at $1.0 \%$ of weight NT replacement. The fresh properties of concrete were discussed in terms of setting time. Results indicate a decrease in setting time by increasing the content of NT. Generally, the partial replacement by NT increases the flexural and indirect tensile strength of concrete but decreases its setting time.

Meng et. al. [4] studied the impact of NT on cement mortar in term of mechanical properties. They reported that replacing cement by NT increases the strength of mortar at early ages whereas strength and fluidity at later ages decrease. The main reason for decreasing of devolpment strength may be attributed to change tendency of diffraction intensity of (001) crystal plane which was totally different with (101) crystal plane. This also leads to modification and reduction of orientation index for the nucleus function, not the amount of hydration products generated. So it may be useful for strength and fluidity properties at later ages to add both the slag powder and superplasticizer with NT.

Nazari et. al. [5] have carried out strength and water absorption coefficient evaluation of high performance-self compacted concrete with different percentages of NT. The results showed that the strength and water permeability resistance of the samples were improved by adding NT to the paste up to $4.0 \%$, depending on increasing crystalline $\mathrm{Ca}(\mathrm{OH}) 2$ amount especially at the early age. NT could rapidly generate $\mathrm{C}-\mathrm{S}-\mathrm{H}$ gel and hence improve the strength of the concrete specimens. NT plays an important role as nanofiller and minimizes the pore structure of the samples by reducing harmful pores. Several empirical functions had been suggected to predict indirect tensile and flexural strength of the samples from compressive strength. On the other hand, the calorimetry tests result in an accelerated peak presence, a lot of weight loss in thermogravimetric analysis and more rapid appearance of the peaks related to generate hydration products. Moreover X-ray diffraction results indicate that NT could increase mechanical and improve physical properties of the concrete samples.

Jayapalan et. al. [6] focused on the utilization of nanomaterials in cementitious composite to achieve a myriad of innovations from new functionality to improve the mechanical properties aiming to understand benefits and costs of using nanomaterials compared to relatively less energy-intensive; and consequently less costly; microparticles. Accordingly, they studied the impact of chemically inert nano and microparticles (titanium dioxide (TiO2) 
Mohamed S. Khalafalla, et al., Improving the mechanical and durability properties of cement ........

and calcium carbonate $(\mathrm{CaCO} 3)$ on the behavior of cement-based materials at early age. Test results indicate that the size of fillers has the ability to optimize and modify the hydration products, shrinkage, and pore structure of cement composites. NT could offset initial higher environmental impacts in terms of its photocatalytic reactivity. Consequently, construction industry will have revolution through optimally sized nanoparticles which play an important role for enhancing properties and structure of cement-based composites, with well- preserved environmental sustainable through the selection of lower embedded-energy particles.

Sustainable needs to improve the physical and mechanical properties of cement mortar to be more applicable with environmental and climate change. Utilization of unique properties of nano-materials to improve cement mortar properties through enhancing the arrangement of molecular structure is the purpose of this research.

\section{Experimental program}

The experimental program is divided into two main phases; the first has been designed to intensively investigate the optimum mixing procedure and investigate the mechanical properties. This phase was conducted at the Materials Testing Lab- Cairo University. The second phase has been designed to intensively investigate the physical properties and micro structure characteristics of the different investigated mixes. This phase was conducted at Housing and Building Research Centre (HBRC) and Central Metallurgical Research Institute (CMRI). Cement mortar properties, measured in the previously mentioned two phases of this research depend on two factors Nano Titanium content and age of curing

\section{Materials}

It is necessary to use proper materials to produce special cementitious composite for different important utilization. Therefore, all materials that were involved in the presented experimental work were selected from local sources in Egypt except nano Titanium. Properties of the materials used are presented as follows.

\subsection{Nano Titanium (NT)}

Titanium oxide nanoparticle ( $\mathrm{TiO} 2)$ with high purity is used. Titanium oxide nanoparticle is mainly anatase phase content. The physical properties of Titanium Nano particles are listed in Table 1 and clearly shown in Figure 1.

Table 1.

Physical Properties of Titanium nanoparticles

\begin{tabular}{|c|c|c|c|}
\hline Diameter $(\mathrm{nm})$ & Surface area $\left(\mathrm{m}^{2} / \mathrm{g}\right)$ & Density $\left(\mathrm{g} / \mathrm{cm}^{3}\right)$ & Purity $(\%)$ \\
\hline $10-30$ & $50-150$ & $<0.15$ & 99.5 \\
\hline
\end{tabular}

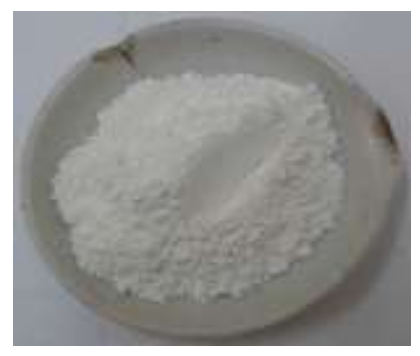

Fig. 1. TiO2 Nanoparticles 


\subsection{Cement}

Commercially available Portland cement (CEM I $42.5 \mathrm{~N}$ ) of surface area $3500 \mathrm{~cm}^{2} / \mathrm{g}$ and specific gravity $3.15 \mathrm{~g} / \mathrm{cm}^{3}$ was used, its properties agree with [7] The chemical properties of the cement are shown in Table 2.

\section{Table 2.}

Chemical Composition of Portland cement

\begin{tabular}{|c|c|c|c|c|c|c|c|c|c|}
\hline $\begin{array}{c}\text { Chemical } \\
\text { Composition }\end{array}$ & $\mathrm{SiO}_{2}$ & $\mathrm{Al}_{2} \mathrm{O}_{3}$ & $\mathrm{Fe}_{2} \mathrm{O}_{3}$ & $\mathrm{CaO}$ & $\mathrm{MgO}$ & $\mathrm{SO}_{3}$ & $\mathrm{NaO}$ & $\mathrm{K}_{2} \mathrm{O}$ & $\begin{array}{c}\text { Loss On } \\
\text { Ignition }\end{array}$ \\
\hline$\%$ & 20.39 & 5.6 & 3.43 & 63.07 & 2.91 & 0.7 & 0.38 & 0.35 & 2.06 \\
\hline
\end{tabular}

\section{Fine aggregate}

Fine aggregate, is locally available natural siliceous sand with a fineness modulus of 2.34. The Chemical and physical properties of the fine aggregate are shown in Table 3. The used sand is well graded according to [8]. The grading curve of fine aggregate with the upper and lower limits of the [8] is shown in Figure 2.

Table 3.

Physical Properties of Fine Aggregate

\begin{tabular}{|c|c|c|c|c|c|c|c|c|}
\hline $\begin{array}{c}\text { Physical } \\
\text { Prop. }\end{array}$ & $\begin{array}{c}\text { Specific } \\
\text { Gravity }\end{array}$ & $\begin{array}{c}\text { Unit } \\
\text { Weight }\end{array}$ & $\begin{array}{c}\text { Fineness } \\
\text { Modulus }\end{array}$ & PH & $\begin{array}{c}\text { TDS } \\
\text { PPM }\end{array}$ & $\begin{array}{c}\text { CL } \\
\text { PPM }\end{array}$ & $\begin{array}{c}\text { SO3 } \\
\text { PPM }\end{array}$ & CaCo3 \\
\hline Value & 2.64 & 1.81 & 2.34 & 8.4 & 276 & 49 & 35 & $0 \%$ \\
\hline
\end{tabular}

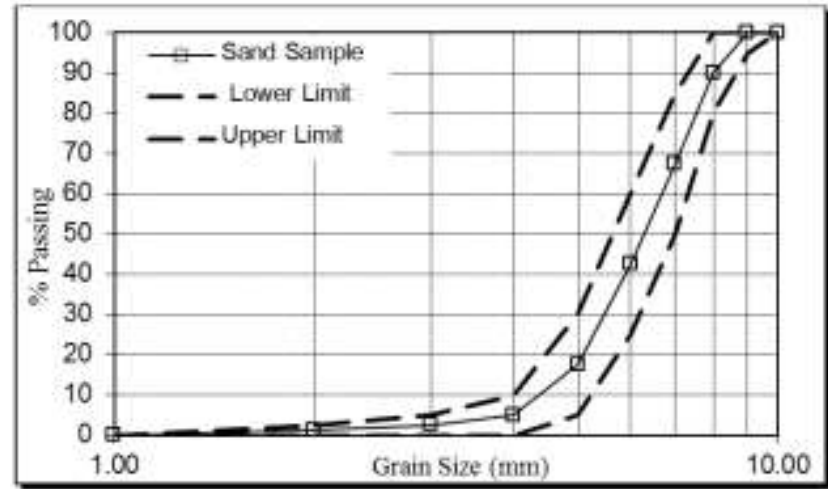

Fig. 2. Grain Size Distribution of Sand

\section{Water}

Potable water is used as mixing water for the production of all tested cement mortars.

\section{Superplasticizer}

A high range water reducer without retarding effect has been used for both concrete and mortar mixes. A $2 \%$ dose has been used to produce the required workability. Table 4 indicates some of the physical and chemical properties of the polycarboxylate admixture used in this study. 
Mohamed S. Khalafalla, et al., Improving the mechanical and durability properties of cement ........

Table 4.

Physical and chemical properties of the polycarboxylate admixture used

\begin{tabular}{|c|c|c|c|c|c|c|c|}
\hline Appearance & $\begin{array}{c}\text { Solid } \\
\text { residue }\end{array}$ & $\mathrm{pH}$ & $\begin{array}{c}\text { Specific } \\
\text { gravity }\end{array}$ & $\begin{array}{c}\text { Rotational } \\
\text { Viscosity } \\
(\mathrm{MPa})\end{array}$ & $\mathrm{C} \%$ & $\mathrm{Na}^{+} \mathrm{PPM}$ & $\mathrm{K}^{+} \mathrm{PPM}$ \\
\hline $\begin{array}{c}\text { Yellow- } \\
\text { Brown } \\
\text { Liquid }\end{array}$ & $36 \%$ & 6.6 & 1.10 & 79.30 & 52.25 & 9150 & 158 \\
\hline
\end{tabular}

\section{Sample preparation}

Cement mortar mixes used in this study were produced in the laboratory using a rotating six-litre pan mixer as shown in Figure 3. Oiling of the mixer was always carried out before the first intended mix was prepared on the day of casting. The oiling operation limited the effect of the mixer dryness/wetness condition on the first intended mix. Also, it eliminated any doubts regarding the use of a rotating pan mixer on the results of the first intended mix.

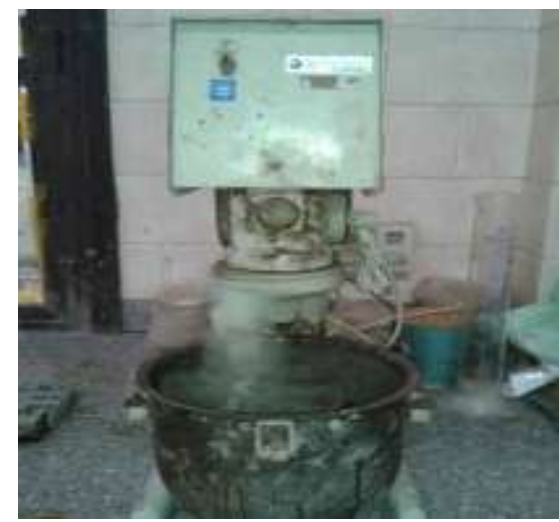

Fig. 3. Rotating Pan Mixer

\subsection{Mixing}

Cement mortar was prepared with cement content $450 \mathrm{~kg} / \mathrm{m}^{3}$ and water-binder (cement + nano titanium) ratio $\mathrm{W} / \mathrm{B}=0.4$. The amount of superplasticizer $\mathrm{SP}$ was $2.0 \%$ of the weight of the binder. The binder to sand ratio for all mixes was set 1:2.69. The cement mortar was produced with $0 \%, 0.5 \%, 1 \%$ and $2 \%$ nano titanium as a partial replacement of cement by weight, as seen in Table 5 .

Producing a homogeneous mortar mix with uniform distribution of the nano titanium depends on introducing the nanoparticles as colloidal dispersion (CT). The adopted mixing procedure starts by adding the dispersion to the super plasticizer and $50 \%$ of the mixing water. This liquid mixture is stirred for 3 minutes at high speed $(120 \mathrm{rpm})$ before adding it to the dry components. Though nano- $\mathrm{TiO}_{2}$ cannot be dissolved in water, a smaller amount of it can be dispersed evenly by super plasticizer, and then water is finally added. 
Table 5.

Constituent materials of the Different Mortar Mixes

\begin{tabular}{|c|c|c|c|c|c|c|}
\hline \multirow{2}{*}{$\begin{array}{c}\text { Mix } \\
\text { Symbal }\end{array}$} & \multirow{2}{*}{ Nano Titanium \% } & \multicolumn{5}{|c|}{ Mixture Components } \\
\cline { 3 - 5 } & & Cement (g) & NT (g) & Sand (g) & Superplasticizer (g) & Water (ml) \\
\hline MT0 & 0.00 & 1859.90 & 0.00 & & & \\
\hline MT0.5 & 0.50 & 1850.60 & 9.30 & & \\
MT1 & 1.00 & 1841.30 & 18.60 & & & \\
MT2 & 2.00 & 1822.70 & 37.20 & & & \\
\hline
\end{tabular}

The standard graded sand, and cement are mixed for $60 \mathrm{sec}$ in the mixer and then approximately $50 \%$ of the liquid compound (superplasticizer was pre-dissolved in water) were added and mixed at medium speed $80 \mathrm{rpm}$ for $60 \mathrm{sec}$ as recommended by [4]. Then the process was stopped for $60 \mathrm{sec}$ and during this period the remaining solution and water was added at the end of the mixing sequence. Afterwards, mixing was re-established for another $120 \mathrm{sec}$. The total mixing time including homogenizing was 5 minutes. The mortar workability was measured using the flow table. One set without titanium nanoparticles was also prepared for the purpose of comparison.

\section{Casting}

The mixes were casted into (70x70x70) mm cubes for compressive strength testing, and $(40 \times 40 \times 160) \mathrm{mm}$ prisms for flexural strength testing. Figure 4 shows same of these samples.

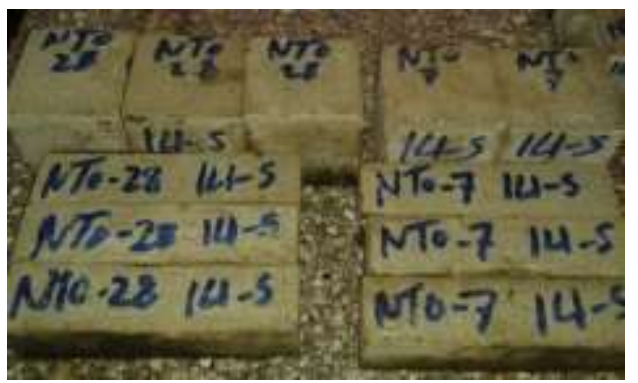

Fig. 4. Cement Mortar Specimens Incorporating NT

\section{Curing}

The samples were stayed for 24 hours in a control room at $20{ }^{\circ} \mathrm{C}$ and $99 \%$ humidity. After that time, they were demoulded and introduced in a saturated lime solution with concentration (4 gram lime to 4 Litre water) to prevent any premature loss of calcium during the remaining 27 days of curing. The water solution is stirred daily. At the end of this period, they were moved into furnace with $105^{\circ} \mathrm{C}$ for drying within $24 \mathrm{~h}$ until a getting constant weight. Finally, the samples were then tested.

\section{Test program}

The testing process is divided into two main phases: mechanical properties testing and physical properties testing after confirming the consistency of fresh properties. 
Mohamed S. Khalafalla, et al., Improving the mechanical and durability properties of cement ........

\subsection{Flow table test}

The flow table test as shown in Figure 5 was performed after mixing, following [9]. This test is widely used to evaluate the workability of cement paste and mortar since it is easy to operate, and allows some parameters such as viscosity to be inferred.

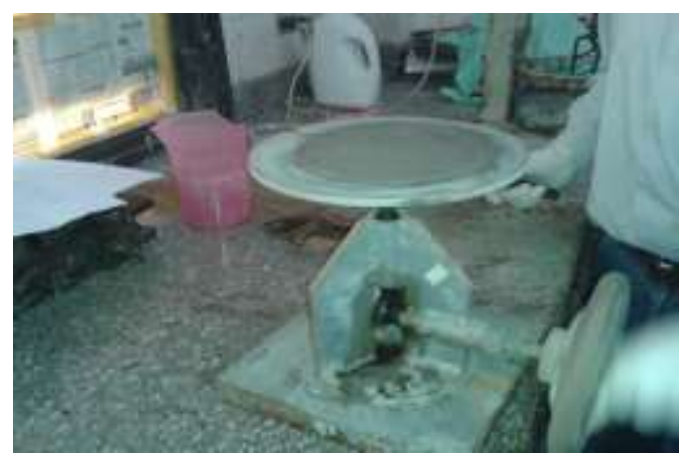

Fig. 5. Flow Table Test

\section{Compressive strength test}

Compressive strength test was carried out according to [10], test method at 7 and 28 days. All specimens were continuously fully water-cured until the time of testing. At any given testing age, three specimens $70 \times 70 \times 70 \mathrm{~mm}$ representing each mortar mix were tested in compression using Universal testing machine under load control and their average value has been reported. The rate of loading was $0.24 \mathrm{MPa} / \mathrm{sec}$.

\section{Flexural strength test}

Flexural strength test was carried out according to [11] test method at ages of 7, and 28 days. All specimens were continuously fully water-cured until the time of testing. At any given testing age, three specimens of size 40x40x160 mm representing each mortar mix were tested in 3 point bending and the average flexural strength value has been reported. Figure 6 shows the universal testing machine used in the test. The samples were tested under load control according to specimen's volume where for cement paste and mortar was $0.24 \mathrm{MPa} / \mathrm{sec}$.

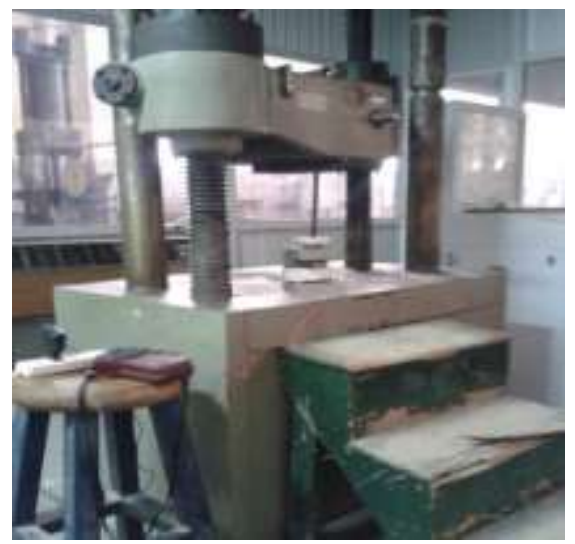

Fig. 6. Compression and Flexure Strength apparatus 
670

JES, Assiut University, Faculty of Engineering, Vol. 43, No. 5, September 2015, pp. 663 - 681

\section{X-ray diffraction (XRD)}

The XRD test was carried out on the different raw materials according to [12]. XRD could be defined as a tool used for identifying the crystal structure.

\section{Pore size distribution (Porosity)}

Pore sizer 9320 is a 30,000 psi mercury porosimeter used to measure the volume distribution of pores in material by mercury intrusion or extrusion. By these measurements, the durability level can be debatable.

\section{Scanning electron microscopy test}

Scanning electron microscopy (SEM) (FEI- Inspect S) was used to examine the microstructure of the different mixes and observe the surface of the specimens. SEM is shown in Figure 7. The SEM examination was conducted according to [13].

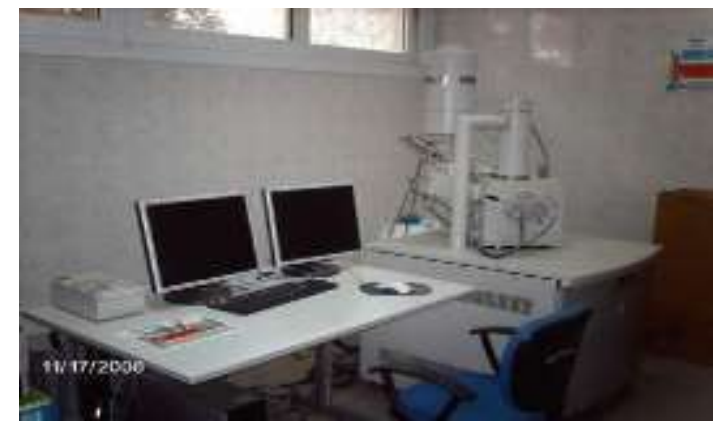

Fig. 7. Scanning Electron Microscopy

\section{Results and Discussions}

\subsection{Fresh properties of cement mortar}

Flow table test refers to the consistency of cement mortar incorporating different percentage of nano titanium

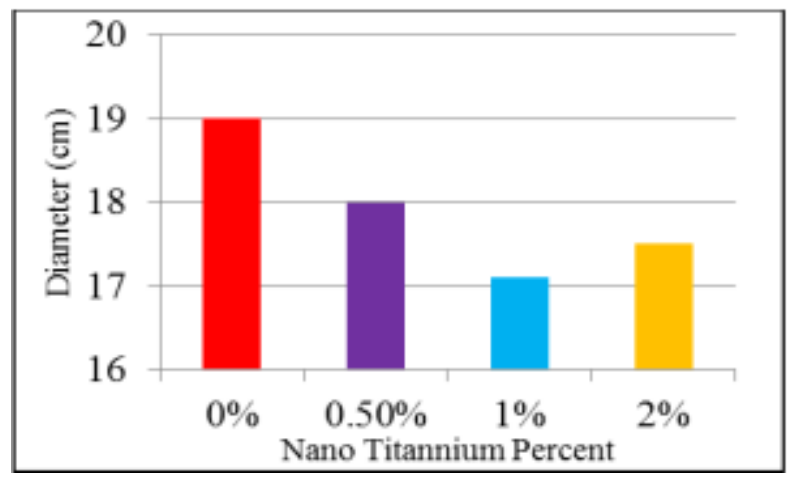

Fig. 8. Assessment of fresh properties of Cement Mortar incorporating NT

Flow diameter is generally, inversely proportional to NT percentage. However at NT percentage of $2 \%$ as partial replacement cement, a consistent increase in flow diameter is observed, which is resulted from agglomerates phenomena. NT is hydrophilic material (the capability of NT to absorb the mixing water). So the increasing in NT content in a mortar mix at 
Mohamed S. Khalafalla, et al., Improving the mechanical and durability properties of cement ........

the same water content leads to observed flow diameter reduction. This effect is observed as long as NT content is not large to the extent that produces agglomerates that keep large portion of NT isolated from water. It may explain the reason of increasing flow diameter when increasing NT content to $2 \%$ of cement weight. Figure 8 indicates that $1 \%$ of partial replacement of cement is the best content present age to have more density through filling the pores.

\subsection{Mechanical properties}

\subsubsection{Compressive strength}

The average compressive strength at the ages of 7 and 28 days were determined. The results indicate that the strength of specimens are improved by adding $\mathrm{TiO}_{2}$ nanoparticles in the cement paste up to $1.0 \mathrm{wt} \%$. $\mathrm{TiO}_{2}$ nanoparticles, as a result of increased crystalline $\mathrm{Ca}(\mathrm{OH}) 2$ amount especially at the early age of hydration, could accelerate $\mathrm{C}-\mathrm{S}-\mathrm{H}$ gel formation and hence increase the strength of the mortar specimens. In addition, TiO2 nanoparticles are able to act as nano fillers and recover the pore structure of the specimens by decreasing harmful pores. [14] mention to the mortar incorporation NT could lead to reduce the porosity and $\mathrm{Ca}(\mathrm{OH}) 2$ content of the interfacial zone. It also reduces the width of the interfacial zone between sand and paste compared with control specimens. This could lead to improve the mechanical properties.

Figure 9 provides the average compressive strength of all samples at the ages of 7 and 28 day. It can be noticed that $1 \%$ NT improves compressive strength by $20.20 \%$ and $27.52 \%$ at 7 and 28 days respectively. Higher content of NT provides less compressive strength improvement. This result encourages NT utilization to get early high strength for special structures. This fact refers to that the NT content in mixture is higher than the amount required to combine with the liberated lime during the process of hydration thus leading to excess silica leaching out and causing a deficiency in strength as it replaces part of the cementitious material but does not contribute to strength. Also, it may be due to the defects generated in dispersion of NT that causes weak zones.

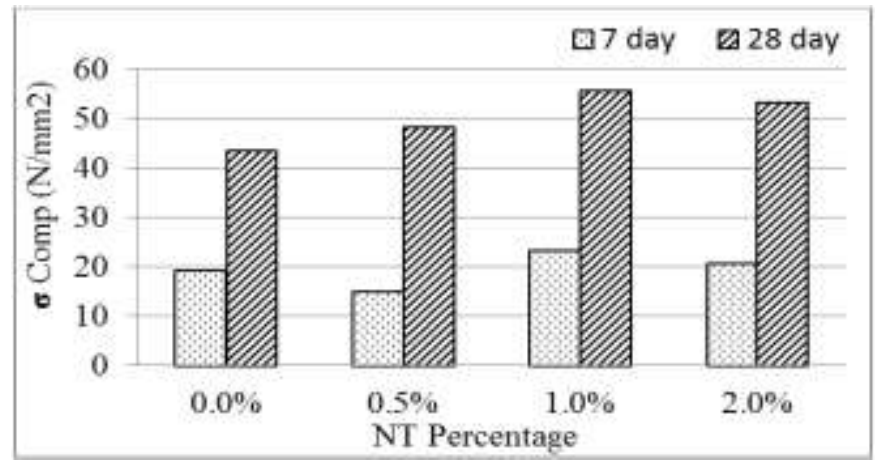

Fig. 9. Assessment of Compressive Strength of Mortar with NT

\subsubsection{Flexural strength}

The average flexure strength could be concluded in Chart 10, was observed negligible improvement (1.25\% and $6.29 \%$ at 7 and 28 day respectively) by adding $1 \%$ replacement of anatase NT with respect to the plain cement. The flexural strength was calculated by following equation

$$
\sigma=\frac{3}{2} * \frac{F^{2} l}{b t^{2}}
$$




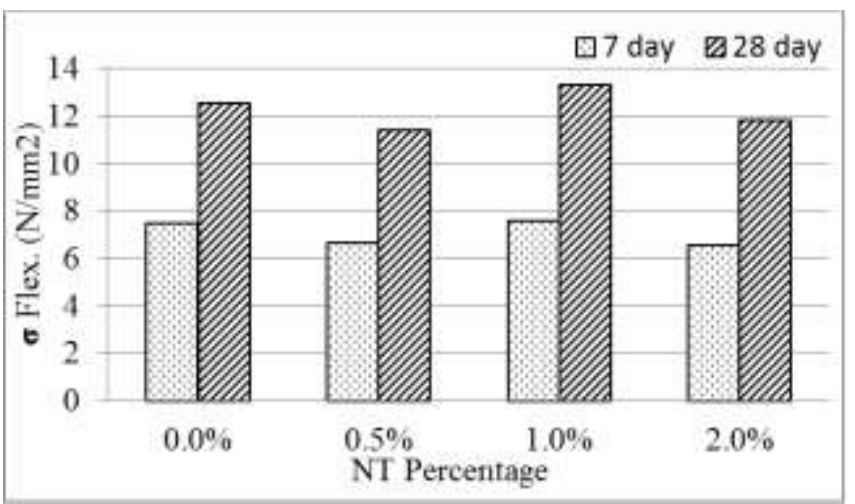

Fig. 10. Assessment of Flexure Strength of Mortar with NT

\section{Static modulus of elasticity and ductility}

The static modulus of elasticity was measured according to Egyptian code 203-test methods. Where specimens were loaded in compression till elastic stage, then the load was removed. The readings were taken 3 times for load and displacement, and then the average was recorded. The comparison between plain sample and the best mechanical proportion of NT at ages of 7 and 28 days for mixes are shown in Table 6 . The more ratio of NT in mortar the more increase in values of modulus of elasticity up to $1 \%$ in early and later age. On the other hand, the ductility (area under curve) enhances the ability to absorb the energy by about $14 \%$ and $58 \%$ for 7 and 28 days respectively at best of incorporating NT.

Table 6.

Elastic Modulus and Ductility Compression for Best Percent of Cement Mortar content NT and Control

\begin{tabular}{|c|c|c|c|c|c|c|c|}
\hline Matrix & Age & NT\% & $\begin{array}{c}\mathrm{E} \\
\left(\mathrm{N} / \mathrm{mm}^{2}\right)\end{array}$ & $\begin{array}{c}\text { A } \\
\text { Area under } \\
\text { curve }\end{array}$ & $\sigma_{\mathrm{t}} / \sigma_{\mathrm{c}}(\%)$ & $\begin{array}{c}\Delta \mathrm{E} \\
\left(\frac{\mathrm{E} 1 \%-\mathrm{E} 0 \%}{\mathrm{E} 0 \%}\right)\end{array}$ & $\begin{array}{c}\Delta \mathrm{A} \\
\left(\frac{\mathrm{A} 1 \%-\mathrm{A} 0 \%}{\mathrm{~A} 0 \%}\right)\end{array}$ \\
\hline \multirow{4}{*}{$\begin{array}{l}\text { Mortar } \\
\text { with NT }\end{array}$} & \multirow{2}{*}{$7 \mathrm{~d}$} & $0 \%$ & 8065.5 & 0.028 & $38.8 \%$ & \multirow{2}{*}{$20.6 \%$} & \multirow{2}{*}{$13.9 \%$} \\
\hline & & $1 \%$ & 9729.9 & 0.032 & $32.8 \%$ & & \\
\hline & \multirow{2}{*}{$28 \mathrm{~d}$} & $0 \%$ & 29909.2 & 0.041 & $28.8 \%$ & \multirow{2}{*}{$18.1 \%$} & \multirow{2}{*}{$58.1 \%$} \\
\hline & & $1 \%$ & 35325.2 & 0.064 & $24.0 \%$ & & \\
\hline
\end{tabular}

18.1. Physical properties of cement mortar

The capillary porosity is distinguished by very small pores which constitute a network of open pores. The permeability of this network is very low, and greatly controls the permeability of concrete. So it was not the appropriate way to use nano materials to control capillary porosity. NT is the best material because its properties matches with this propose, where it has high specify density, superb fine particles size and good flow properties result in packing condition due to better consolidation. This leads to decreasing porosity and permeability mortar. Therefore, in this section, it will be focused on physical especially porosity properties, through clarifying the behavior of samples by many ways. 
Mohamed S. Khalafalla, et al., Improving the mechanical and durability properties of cement ........

\subsection{X-Ray Diffraction Test Result}

\subsubsection{Cement}

$\mathrm{X}$-Ray diffraction pattern of cement specimen is shown in Figure 11. It should be noted that there are several aspects for comparison such as chemical composition, type of crystal structure, unit cell parameters and fractional atomic parameters.

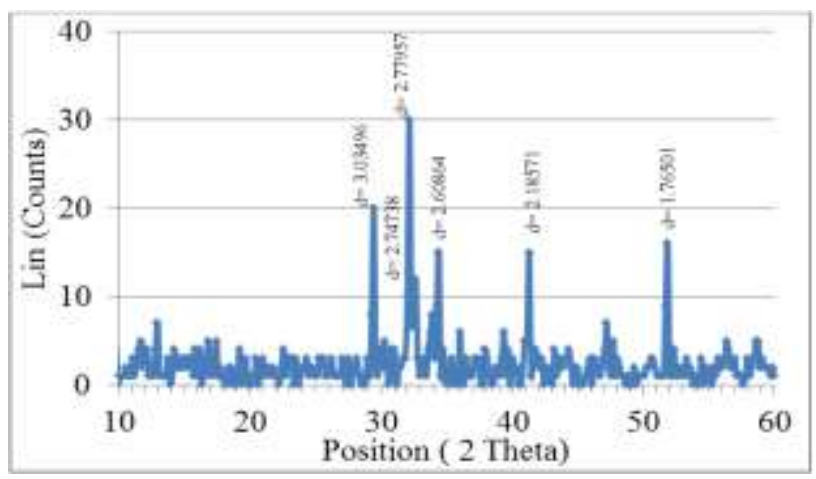

Fig. 11. XRD of cement Powder

From pervious pattern, there are many peaks which are related to different compounds. These compounds can be classified into three main elements as summarized in Table 7. It can be noted that, the two elements $\mathrm{Al}$ and $\mathrm{Fe}$ are not existing at all. From PDF card, sample data can match the database to identify the phase. This is classified as C2S larnite, C3S Hatrurite, and $\mathrm{CaCO} 3$ calcite. Bearing in mind, there is no meaning to determine the cement crystal size because of its ability to rapid changing even in simple environmental condition

\section{Table 7.}

Summary of distinguishing features of different components present in cement powder.

\begin{tabular}{|c|c|c|c|c|c|}
\hline Phase & $\begin{array}{l}\text { Chemical } \\
\text { Composition }\end{array}$ & Polymorphs & $\begin{array}{l}\text { PDF } \\
\text { card }\end{array}$ & Content $\%$ & $\begin{array}{ll}\begin{array}{l}\text { Distinct features of } \\
\text { diffractograms }\end{array} \\
\end{array}$ \\
\hline \multirow{2}{*}{ Belite "C2S" } & \multirow{2}{*}{$\begin{array}{l}\mathrm{Ca} 2(\mathrm{SiO} 4) \\
\text { Larnite }\end{array}$} & $\beta-\mathrm{C} 2 \mathrm{~S}$ & \multirow{2}{*}{$83-0461$} & \multirow{2}{*}{45.6} & $\begin{array}{l}\text { Strong peaks between } \\
(33-34))^{\circ} \text { and at } 34.2^{\circ}\end{array}$ \\
\hline & & $\gamma-\mathrm{C} 2 \mathrm{~S}$ & & & Strong peaks at $41.5^{\circ}$ \\
\hline \multirow{3}{*}{ Alite "C3S" } & \multirow{3}{*}{$\begin{array}{l}\mathrm{Ca} 3(\mathrm{SiO} 4) \\
\text { Hartrurite }\end{array}$} & Monoclinic M3 & \multirow{3}{*}{$85-1378$} & \multirow{3}{*}{43.3} & $\begin{array}{l}\text { Strong peak with a } \\
\text { shoulder at } 32.5^{\circ}\end{array}$ \\
\hline & & Triclinic T & & & Triplet at $34.5^{\circ}$ \\
\hline & & Rhombohedral, R & & & Strong singlet at $41.5^{\circ}$ \\
\hline Lime & $\begin{array}{l}\mathrm{Ca}(\mathrm{Co} 3) \\
\text { Calcite }\end{array}$ & 3.03496 & $88-1808$ & 11.1 & $\begin{array}{l}\text { Strong peak with a } \\
\text { shoulder at } 29.4^{\circ}\end{array}$ \\
\hline
\end{tabular}

\subsubsection{Nano titanium}

$\mathrm{X}$-Ray diffraction pattern of nano titanium sample is shown in Figure 12. One strong peak cantered on a $2 \theta$ of $24-26^{\circ}$ as shown, it's indicating the characteristics of anatase titanium dioxide with crystal size $21.9 \mathrm{~nm}$, which could be confirmed from PDF-card which has series number 84-1286. 


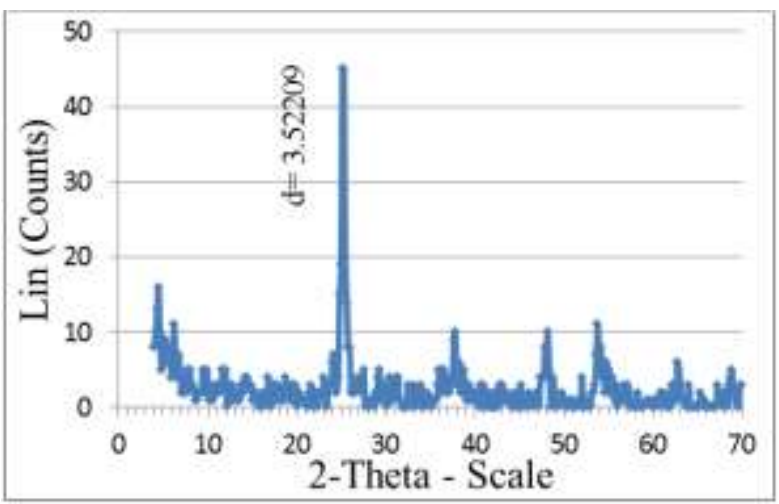

Fig. 12. XRD of Nano-Titanium (TiO2)

\section{Mercury intrusion porosimetry (MIP) test result}

\subsection{Effect of NT on pore structure at 7 day of curing}

The relationships between different obtained results were evaluated to compare the pore structure of the mortars incorporating different percentage of NT. The most important output data of MIP for the studied mortars are summarized in Table 8.

Table 8.

Summary of porosity data of mortar After 7 day of curing

\begin{tabular}{|l|c|c|c|c|}
\hline Mix & $\mathbf{0 \%}$ & $\mathbf{0 . 5 0 \%}$ & $\mathbf{1 . 0 \%}$ & $\mathbf{2 . 0 \%}$ \\
\hline Sample weight $(\mathrm{g})$ & 1.5724 & 1.4299 & 1.6784 & 1.7933 \\
\hline Total intrusion volume $(\mathrm{ml} / \mathrm{g})$ & 0.1111 & 0.0797 & 0.0672 & 0.0668 \\
\hline Median diameter $($ volume $)(\mu \mathrm{m})$ & 0.0118 & 0.0464 & 0.0441 & 0.0530 \\
\hline Median diameter $($ area $)(\mu \mathrm{m})$ & 0.0511 & 0.0112 & 0.0110 & 0.0110 \\
\hline Average pore diameter $(\mu \mathrm{m})$ & 0.0233 & 0.0248 & 0.0234 & 0.0255 \\
\hline Apparent density $(\mathrm{g} / \mathrm{ml})$ & 3.0311 & 3.1130 & 3.0260 & 3.0165 \\
\hline Bulk density $(\mathrm{g} / \mathrm{ml})$ & 2.2676 & 2.4941 & 2.5147 & 2.5105 \\
\hline Total pore surface area $\left(\mathrm{m}^{2} / \mathrm{g}\right)$ & 8.693 & 12.878 & 11.470 & 10.488 \\
\hline Total Porosity $(\%)$ & 25.19 & 19.88 & 16.90 & 16.78 \\
\hline
\end{tabular}

The obtained results of total pore volume of cement mortars showed that the total pore volume of all mortar specimens incorporating NT is lower than plain mortar. The total pore volume was decreased by increasing the NT content. Thus improve efficient of the density and porosity properties by $9.67 \%$ and $33.38 \%$ at $2 \%$ wt. replacement as a best percent of incorporating subsequently improve the durability.

The cumulative intrusion volume and the Incremental intrusion volume which refer to pressure, versus pore diameter are shown in Figure 13 and Figure 14 respectively. It can be noticed that, there is a convergence in the behavior of the various ratios of NT mortar with each other, compared with plain mortar for the above mentioned in pore structure aspects. Therefore, the cumulative intrusion volume is decreasing by increasing the NT powder 
content in mortar mixtures especially at the higher pore pressure values and their values are higher than those of the corresponding control specimen mixtures. On the other hand, the incremental intrusion volume indicated to the most pore diameters of control specimen's between $(0.40$ to 2.0$) \mu \mathrm{m}$, while the NT mortar specimens have a pore diameters between (0.03 to 0.08$) \mu \mathrm{m}$ with a convergence in two specimens $0.50 \%$ and $1.0 \%$, indicating improvement in the homogeneity of consistency. At $2 \%$ replacement, it is noticed decrease in incremental intrusion volume in spite of the most pore diameters in the medium of the range.

A noticeable change after 7 day of curing was found, the more NT in cement mortar the more increasing in density and improving in filling the porosity. These changes lead to improve in durability and increase the cementitious composite age. There are some convergent results between two samples $1.0 \mathrm{wt} \%$ and $2.0 \mathrm{wt} \%$ and there are some differences. This difference does not make up the vast price difference between its contents.

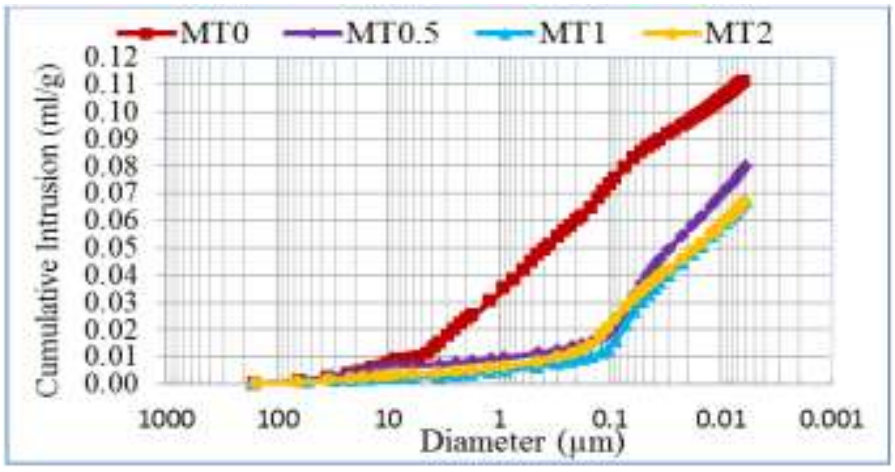

Fig. 13. Cumulative Intrusion and Diameter Chart of NT-Cement Mortar at 7 Days

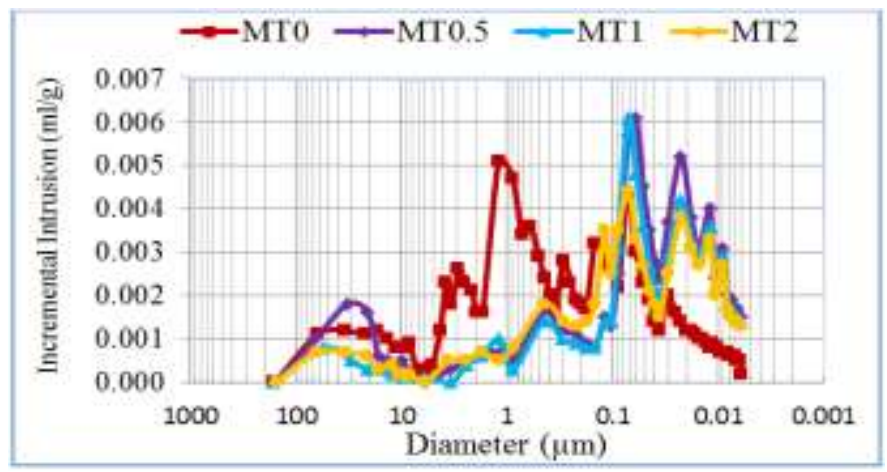

Fig. 14. Incremental Intrusion and Diameter Chart of NT-Cement Mortar at 7 Days

\subsection{Effect of $N T$ on pore structure at 28 day of curing}

The most important output data of MIP for the studied mortars are summarized in Table 9. Where the results of total pore volume of cement mortars showed that the total pore volume of all mortar specimens incorporating NT is lower than plain mortar. The total pore volume was decreasing by increasing the NT content, indicating improvement in durability state of samples by increasing the density and porosity by $7.87 \%$ and $29.07 \%$ respectively at $1 \%$ wt. replacement. It is also noted that, sample $1.0 \mathrm{wt} \%$ replacement corresponded with sample of $2.0 \mathrm{wt} \%$.

The cumulative intrusion volume and the incremental intrusion volume versus pore diameter showed the pore structure distribution in Figure 15 and Figure 16 respectively. It 
can be noticed that, there is a convergence in the behavior of the various ratios of NT mortar with each other, compared with plain mortar for the above mentioned in pore structure aspects. Therefore, the cumulative intrusion volume is decreasing by increasing the NT powder content in mortar mixtures especially at the higher pore pressure values and their values are higher than those of the corresponding control specimen mixtures.

Table 9.

Summary of porosity data of mortar After 28 day of curing

\begin{tabular}{|l|c|c|c|c|}
\hline Mix & $\mathbf{0 \%}$ & $\mathbf{0 . 5 0 \%}$ & $\mathbf{1 . 0 \%}$ & $\mathbf{2 . 0 \%}$ \\
\hline Sample weight $(\mathrm{g})$ & 1.9012 & 1.9446 & 2.2392 & 1.8460 \\
\hline Total intrusion volume $(\mathrm{ml} / \mathrm{g})$ & 0.0987 & 0.0764 & 0.0667 & 0.064 \\
\hline Median diameter $($ volume $)(\mu \mathrm{m})$ & 0.2009 & 0.0495 & 0.0539 & 0.0543 \\
\hline Median diameter $($ area $)(\mu \mathrm{m})$ & 0.0122 & 0.0121 & 0.0118 & 0.0107 \\
\hline Average pore diameter $(\mu \mathrm{m})$ & 0.0504 & 0.0261 & 0.026 & 0.0252 \\
\hline Apparent density $(\mathrm{g} / \mathrm{ml})$ & 2.9982 & 2.9361 & 2.8964 & 2.9687 \\
\hline Bulk density $(\mathrm{g} / \mathrm{ml})$ & 2.3125 & 2.3981 & 2.4272 & 2.4946 \\
\hline Total pore surface area $(\mathrm{m} 2 / \mathrm{g})$ & 7.841 & 11.706 & 10.25 & 10.171 \\
\hline Total Porosity $(\%)$ & 22.84 & 18.32 & 16.2 & 15.97 \\
\hline
\end{tabular}

On the other hand, the incremental intrusion volume indicate to the most pore diameters of control specimen's between ( 0.1 to 0.4$) \mu \mathrm{m}$, while the NT mortar specimens have a pore diameters between (0.05 to 0.09$) \mu \mathrm{m}$ with also a convergence in two specimens $0.50 \mathrm{wt} \%$ and $1.0 \mathrm{wt} \%$, Indicating improvement in the homogeneity of consistency. It was noticed also that the behavior of " $2 \mathrm{wt} \%$ replacement" was continued decreasing in Incremental intrusion volume although that the most pore diameters in the medium of the range.

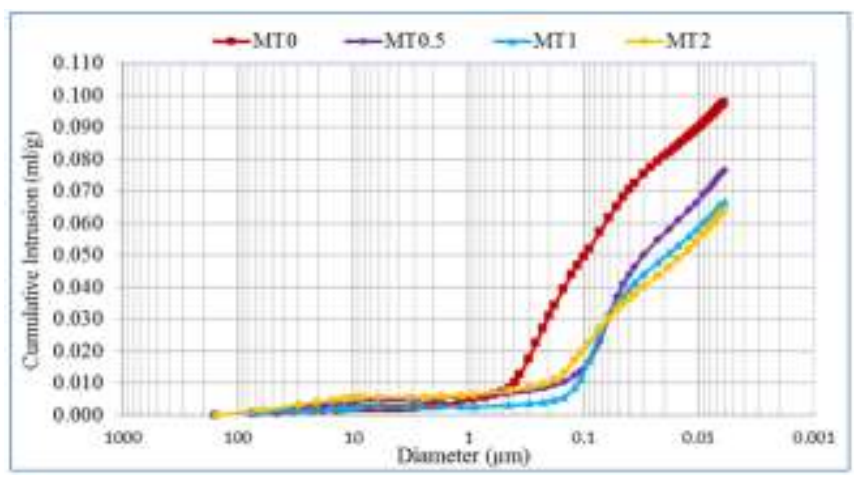

Fig. 15. Cumulative Intrusion and Diameter Chart of NT-Cement Mortar at 28 Days

As conclusion, after 28 day of curing, more NT in cement mortar more increasing in density and improving in filling the porosity. These changes lead to more improvement in durability and increase the cementitious composite life. There are similar and convergent results between two samples $1.0 \mathrm{wt} \%$ and $2.0 \mathrm{wt} \%$ replacement. Therefore, it can be suggested prolong curing, increase the ages and percentages of $\mathrm{TiO} 2$ nanoparticles leads to reduction in permeable voids. This is due to the high action and filler effects of $\mathrm{TiO} 2$ nanoparticles. 


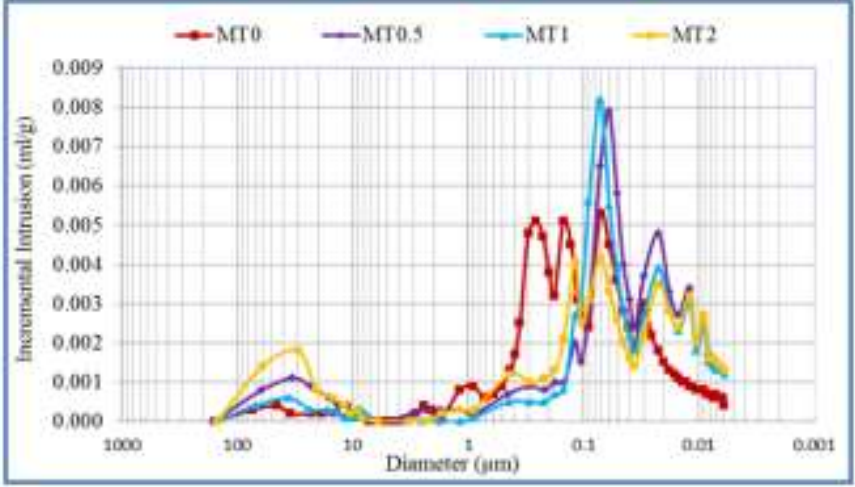

Fig. 16. Incremental Intrusion and Diameter Chart of NT-Cement Mortar at 28 Days

\section{Scanning electron microscopy test analysis.}

Finally, the scanning electron microscope (SEM) shows micrographs of control specimen and best strength proportion of NT replacement. In addition to identify surface of cement and $\mathrm{TiO} 2$ powder. On the other hand, the elemental analysis (EDAX) for best strength was tested to identify the compounds. The morphological analysis evinced no substantial differences in either the form or the texture of the different reaction products in mortar with plain admixtures.

\subsection{SEM of powder}

The cement and anatase NT powders are shown in Figures 17 Cement scan as hexagonal crystals which indicate to tricalicum silicate $(\mathrm{C} 3 \mathrm{~S})$. The dicalcium silicate $(\mathrm{C} 2 \mathrm{~S})$ shows as spherical morphology. While approximately no trace of C3A and C4AF.

NT indicates some agglomeration may be due his hydrophilicity property. As $\mathrm{TiO} 2$ is exposed to UV light, it becomes increasingly hydrophilic (attractive to water), thus it can be used for anti-fogging coating for self-cleaning windows. On the other hand the Figure shows $\mathrm{TiO} 2$ as spherical form. While the purity up to $99 \%$ without any traces as shown.

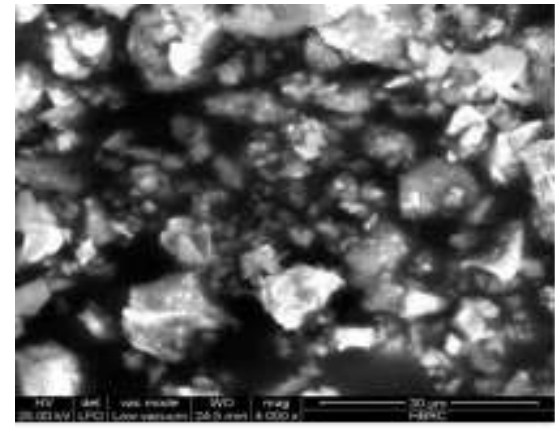

a. Cement powder

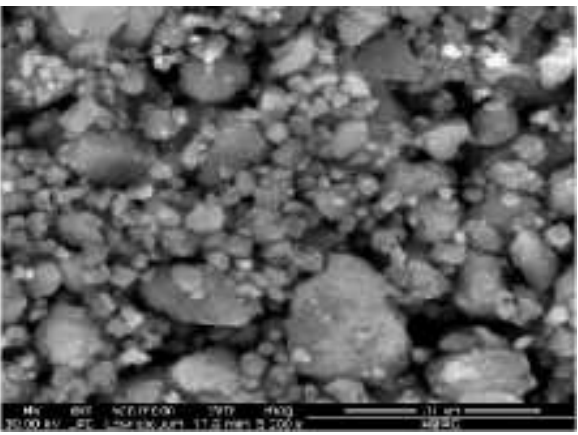

b. NT Powder

Fig. 17. SEM of Cement Powder

\subsection{SEM at 7 day}

The fracture surface of the $0 \%$ NT/cement mortar is shown in Figure 18.a, and it consists of a combination of smooth and rough areas typical of fracture features of cementitious material. The $1 \mathrm{wt} \%$ NT replacement specimen scanning Figure 18.b shows 
678

JES, Assiut University, Faculty of Engineering, Vol. 43, No. 5, September 2015, pp. 663 - 681

more density microstructure with lesser voids than pervious mix. The increment of NT percentage improves the packing density of the mix. It should be noted that, some of NT percentage did not react with hydration process products yet. Another meaning, the hydration products didn't have ability to contented the NT proportion. Its referring to the specimens is starting at interaction stage.

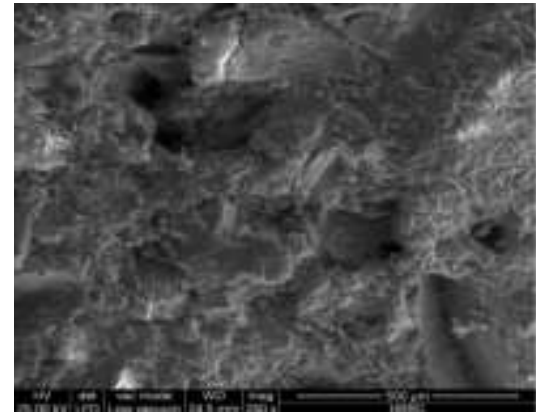

a. Plain Mortar

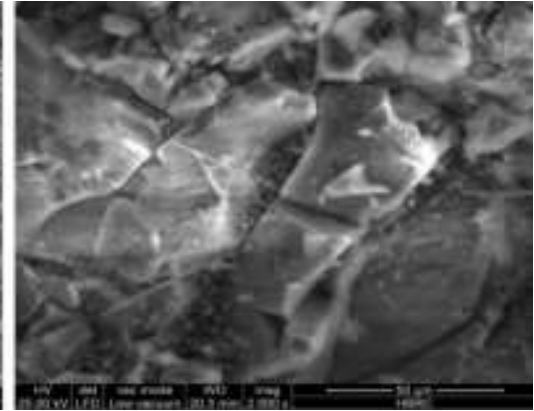

b. $1 \%$ NT

Fig. 18. SEM at 7 Day

\subsection{SEM at 28 day}

Generally, after 28 days the reaction is in progress with a considerable decrease in the amount of anhydrous cement particles. It can be noted, a more compact mixture after this period of curing which indicate rapid formation of $\mathrm{C}-\mathrm{S}-\mathrm{H}$ gel.

The plain cement mortar after 28 day of reaction is shown in Figure 19.a. It is noted that the finial pattern of surface features which indicate to more wrinkles and pores. Whereas, $1 w t \%$ NT replacement specimen scanning Figure 19.b shows more density microstructure with lesser voids control mixture. Although, the hydration products didn't have ability to content the NT, More NT percentage more improving in packing density of the mix. Generally, the voids are lacking whether between hydration produces or free.

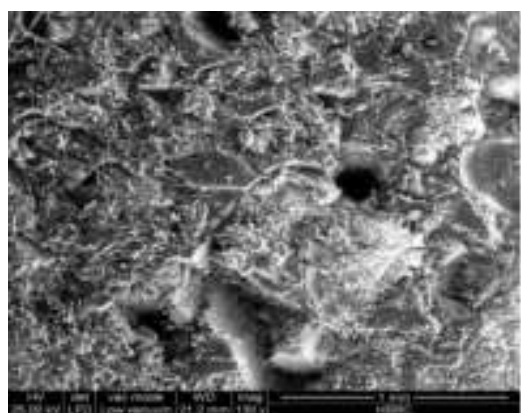

a. Plain Mortar

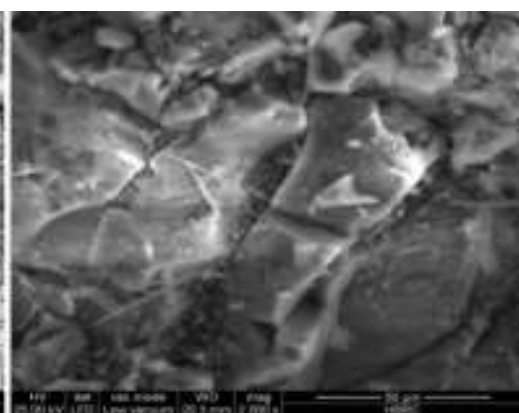

b. $1 \%$ NT

Fig. 19. SEM at 28 day

Table 10 illustrates the elements percent on surface of control and 1\% NT replacement cement by elements weight and atomic weight ratio. It can be note; at control specimens the main elements for interface surface are $\mathrm{Ca}$ and $\mathrm{Si}$, while the content of $\mathrm{Fe}$ and $\mathrm{Al}$ were very small traces. Whereas, there is no any traces of $\mathrm{Fe}$ and $\mathrm{Al}$ appear at $1 \% \mathrm{NT}$ replacement. 
Mohamed S. Khalafalla, et al., Improving the mechanical and durability properties of cement ........

On the other hand, $\mathrm{Ca} / \mathrm{Si}$ atomic weight ratio for interface control specimens was found 0.275 and 0.282 for control and $1 \%$ NT replacement respectively. This mean no leaching of $\mathrm{Ca}(\mathrm{OH}) 2$ than control sample and no improving note in hydration process.

Table 10.

Proportions of the elements in the specimens

\begin{tabular}{|l|c|c|c|c|}
\hline & \multicolumn{2}{|c|}{ Control } & \multicolumn{2}{c|}{$\mathbf{1 \%}$} \\
\hline Element & Weight\% & Atomic Weight \% & Weight\% & Atomic Weight \% \\
\hline C K & 12.33 & 19.09 & 8.95 & 14.26 \\
\hline O K & 49.99 & 58.09 & 50.88 & 60.90 \\
\hline Na K & 0.40 & 0.32 & - & - \\
\hline Mg K & 0.44 & 0.34 & 0.46 & 0.36 \\
\hline Al K & 0.97 & 0.67 & 0.93 & 0.66 \\
\hline Si K & 24.71 & 16.36 & 26.36 & 17.97 \\
\hline S K & 0.46 & 0.26 & 0.47 & 0.28 \\
\hline Cl K & 0.15 & 0.08 & - & - \\
\hline Ca K & 9.70 & 4.50 & 10.61 & 5.07 \\
\hline Ti K & - & - & 0.51 & 0.20 \\
\hline Fe K & 0.84 & 0.28 & 0.84 & 0.29 \\
\hline Total & 100.00 & 100.00 & 100.00 & 100.00 \\
\hline
\end{tabular}

\section{Conclusions}

The cement content, Nano titanium type and homogeneous distribution of it inside cement paste are the three major factors affecting the expected enhancement in physical and mechanical properties of cement paste and mortar. There is a real need to develop the constituents of mixes and standard mixing procedure that can insure the homogeneity distribution of Nano Titanium inside cementitious mixes.

1. Adding $1 \%$ of Nano Titanium to Cement mortar enhances compressive strength by $20.2 \%$ (age of 7 day) and $27.5 \%$ (age of 28 days).

2. There is no significant increase in flexural strength by adding nano titanium to mortar where an improvement of only $1.25 \%$ at early age and $6.29 \%$ at later age were reported.

3. The higher nano titanium content, the more ability to repel water due to its hydrophobic characteristic and its ability to fill the cement paste pores.

4. Nano titanium changes the physical properties of mortar through closing the pores and increasing the density although it does not have ability to accelerate cement hydration.

5. Although the $2 \%$ replacement of cement by nano titanium has an ability to improve the density of mortar by up to $10.71 \%$ which refers to a decrease in porosity to $33.38 \%$ at early age, the $1 \%$ replacement at 28 day of curing limits the porosity to a maximum of $29.07 \%$ and increases the density $4.96 \%$

6. The SEM examination indicates nano titanium acts as better filler between the cement particles up to $1 \%$ replacement.

\section{Acknowledgement}

The authors wish to express their sincere appreciation to Construction Research Institute, National Water Research Centre CRI-NWRC, for the encouragement and the financial support they bestowed me. In addition, Special thanks go to the administration of 
the Housing and Building Research Centre HBRC for the opportunity to complete the work through laboratories.

\section{REFERENCES}

[1] ACI Committee116. "Cement and Concrete Terminology". Manual of concrete practice. American Concrete Institute, Farmington Hills.

[2] Eurpean Nanotechnology, G. (2006). Nanotechnology and construction. Nanoforum Report.

[3] Nazari , A.; Riahi, S.; Riahi Sh.; Shamekhi, S.F.; and Khademno, A.; (2010). Improvement the mechanical properties of the cementitious composite by using $\mathrm{TiO} 2$ nanoparticles. American science, 6, 98-101.

[4] Meng, T.; Yachao, Y.; Qian, X.; Zhan, S.; and Qian K.; (2012). Effect of nano-TiO2 on the mechanical properties of cement mortar. Construction and Building Materials, 29, 241-245.

[5] Nazari, A.; Riahi, S.; (2010), "The effect of TiO2 nanoparticles on water permeability and thermal and mechanical properties of high strength self-compacting concrete. Materials Science and Engineering A, 528,756-763

[6] Jayapalan, A. R.; Lee B. Y.; and Kurtis, K.S.; (2013), Can nanotechnology be 'green'? Comparing efficacy of nano and microparticles in cementitious materials., Cement \& Concrete Composites, 36, 16-24.

[7] Egyptian Standard Specification 4756-1(2007). Cement-physical and mechanical tests.

[8] ASTM C33. (1998). Standered test method for concrete aggregates. In concrete and concrete aggregates (Vol. 4). annual book of astm standards.

[9] The European Guidelines. (1999). Determination of consistence of fresh mortar (by flow table), Specification, Production and Use.

[10] Egyptian.Code. (2007). Design and Execution of Reinforced Concrete Structures, Guide for Laboratory Tests of Concrete Materials. cairo: HSBC.

[11] ASTM C293. (2000). Standard Test Method for Flexural Strength of Concrete (Using Simple Beam with Center-Point Loading) (Vol. 4). concrete and concrete aggregates.

[12] ASTM.E1361-02. (2007). Standard Guide for correction of Interelement Effects in X-Ray Spectrometric Analysis.

[13] ASTM.C1202. (2012). Standard Test Method for Electrical Indication of Concrete's Ability to Resist Chloride Ion Penetration.

[14] Zhang, M.H.; Lastra, R.; and Malhotra, V.M., (1996). Rice-Husk Ash paste and concret: some aspects of hydration and the microstructure of the interfacial zone between the aggregate and paste. cement and concrete research, 26(6), 963-977. 
Mohamed S. Khalafalla, et al., Improving the mechanical and durability properties of cement ........

"تحسين الخصائص الميكاتيكية والمتانة للمونة الأسمنتية باستخدام النانو تاتتيوم"

$$
\text { ملخص البحث: }
$$

إن التطور التكنولوجي اللازم لتحسين خواص المركبات الأسمنتية بأشكالها المختلفة بتميز بمعدله السريع

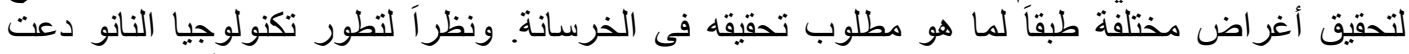

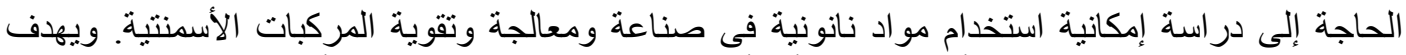

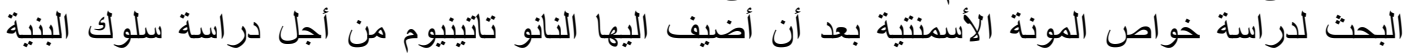

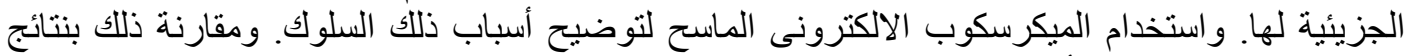

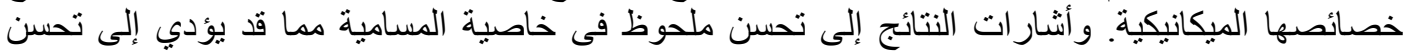

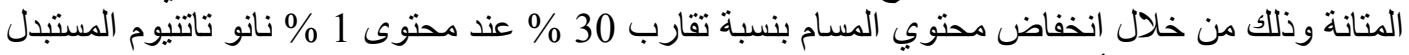

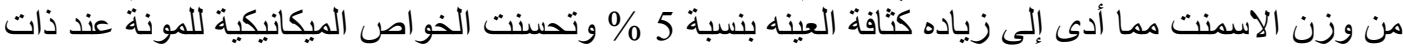

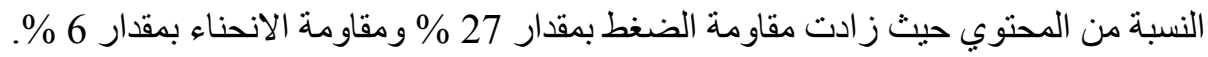

